\title{
Effectiveness of the repair of unstabilised rammed earth with injection of
}

\section{mud grouts}

\author{
R.A. Silva ${ }^{1}$, D.V. Oliveira ${ }^{2}$, L. Schueremans ${ }^{3}$, T. Miranda ${ }^{4}$, J. Machado $^{5}$ \\ 1-2, 4-5 ISISE, University of Minho, Guimarães, Portugal \\ ${ }^{3}$ Department of Civil Engineering, KU Leuven / Frisomat, Belgium
}

Abstract: The presence of cracks debilitates the structural performance of rammed earth. Grout injection is a repair solution put forward recently, where compatibility issues demand using mud grouts. Little is known on this topic, whereby an experimental program on the mechanical effectiveness of grout injection for repairing cracks in rammed earth was performed. Specimens tested under bending and diagonal compression were retested after repair with injection of mud grouts. Mud grouts incorporating the original soil of the rammed earth are shown to perform better and their injection achieves satisfactory shear strength recovery, but is less effective in recovering initial shear stiffness.

Keywords: Earth construction, rammed earth, repair, injection, mud grout, diagonal compression, shear strength, three-point bending, bending strength, experimental program

\section{Highlights:}

- The repair effectiveness of mud grouts is tested;

- The shear behaviour of rammed earth depends on binding, friction and interlocking;

- Mud grouts incorporating the same soil of the rammed earth perform better;

- Grout injection provides satisfactory strength recovery;

- Grout injection is incapable of recovering the initial shear stiffness.

\footnotetext{
${ }^{1} \mathrm{PhD}$, Post-doc researcher, ISISE, University of Minho, Department of Civil Engineering, Azurém, P-4800-058 Guimarães, Portugal. Phone: +351253510 200, fax: +351253510 217, email: ruisilva@ civil.uminho.pt

${ }^{2} \mathrm{PhD}$, Professor, ISISE, University of Minho, Department of Civil Engineering, Azurém, P-4800-058 Guimarães, Portugal. Phone: +351253510 200, fax: +351253510217, email: danvco@ civil.uminho.pt

${ }^{3} \mathrm{PhD}$, Invited Professor, Catholic University of Leuven, Department of Civil Engineering, P-3001, Heverlee, Belgium. Phone: +32 163216 54, fax: +32 1632 19 76, email: luc.schueremans@bwk.kuleuven.be

${ }^{4} \mathrm{PhD}$, Assistant Professor, ISISE \& IB-S, University of Minho, Department of Civil Engineering, Azurém, P-4800-058 Guimarães, Portugal. Phone: +351 253510 200, fax: +351253 510 217, email: tmiranda@ civil.uminho.pt

${ }^{5}$ MSc student, University of Minho, Department of Civil Engineering, Azurém, P-4800-058 Guimarães, Portugal. Phone: +351 253 510 200, fax: +351253510 217, email: juliomachado.85@ gmail.com
} 


\section{INTRODUCTION}

Building in rammed earth consists in compacting moist earth by layers inside a removable formwork to build monolithic walls. The use of a formwork and the ramming process constitute key features that differentiate this technique from other earth construction techniques. The construction process is carried out by courses (like masonry), where the formwork runs horizontally along the perimeter of the construction and then is lifted to build the next course. This type of construction is also associated to the concept of vernacular architecture, meaning that several variations exist, namely regarding the geometry, materials and fabric of the rammed earth [1]. For example, in Alentejo (Portugal) the length of rammed earth blocks from typical dwellings may vary from $1.40 \mathrm{~m}$ to $2.50 \mathrm{~m}$, the height from $0.40 \mathrm{~m}$ to $0.55 \mathrm{~m}$ and the thickness from $0.40 \mathrm{~m}$ to $0.57 \mathrm{~m}$ [2].

Despite the recent age of rammed earth construction relative to other earth construction techniques [3], its use is reported to be thousands of years old [4][5]. This type of construction is present in countries of all inhabited continents, which include the USA, Brazil, Morocco, Portugal, Spain, Germany, India, China, Australia and New Zealand. Rammed earth has been mainly used for building dwellings. Nevertheless, the use of rammed earth also resulted in several monumental and military constructions with important cultural, historical and architectonic value. The Great Wall of China is a good example of such important heritage, where many of its sections were built in rammed earth [5].

In Portugal, there is also an important rammed earth built stock, concentrated in the southern region of the country, namely in the regions of Alentejo, Algarve and Ribatejo. However, it appears more often in southern Alentejo, where there is less rain and other building materials, such as stone and timber, are scarce [1]. In general, the Portuguese rammed earth built stock can be classified according to its use, as civil and military [6]. The first group includes most of the built stock and is associated to the construction of dwellings, windmills, farm storehouses and religious constructions. The second group is mainly constituted by fortifications built during the Islamic presence in Portugal, between the 8th and 13th centuries [7].

Many of the aforementioned constructions are found, nowadays, in poor conservation condition, resulting from lack of maintenance and continuous abandon during the past half-century. This situation contributes for increasing the vulnerability of these constructions [8]. Rammed earth constructions are particularly vulnerable to rainfall and earthquakes [9]. The presence of cracks is a type of damage often present in these constructions, which has particular influence on the structural performance. Cracks constitute preferential paths for rainfall infiltration, moistening directly the rammed earth, substantially reducing its mechanical properties [10]. The 
presence of structural cracks in rammed earth walls decreases their bearing capacity and stiffness, and disrupts the overall monolithic behaviour of the structure.

Nowadays, the rehabilitation of the rammed earth heritage assumes great interest, namely in what concerns its housing and touristic valorisation [11]. Furthermore, Alentejo and Algarve are regions with an important seismic hazard, meaning that lack of proper intervention solutions puts at risk the rammed earth built heritage and the life of eventual inhabitants. Cracks can be repaired using different techniques, but the repair efficiency greatly varies from case to case [9]. The most basic solution consists in simply filling the crack with earth mortar [12]. However, within this procedure it is difficult to re-establish the continuity of the material, since earth mortars tend to loose bond due to shrinkage cracking. Furthermore, in the cases where the crack is thin (less than $~ 30$ $\mathrm{mm}$ ), the wall needs to be cut back [13], making the procedure more complex. These problems can be overcome by injecting a grout sufficiently fluid to completely fill the crack. The grout also needs to be compatible with the rammed earth, meaning that earth should be included in its composition, as suggested by the technical committee of the Getty Conservation Institute for earth construction [14]. Such grouts are known as mud grouts and were used in few reported cases with apparent successful results [15][16]. Very recently, Müller et al. [17] used a binary grout (composed by hydrated lime and pozzolanas) for repairing cracks in cob wallets. This type of grouts is claimed to be also capable of achieving compatibility requirements with earthen materials, while providing lower shrinkage and better control on the strength development than mud grouts. However, the mechanical repair effectiveness of the proposed grout was shown to be very low.

Despite the few research available on mud grouts [18][19][20], Vargas et al. [18] has shown that unmodified mud grouts (without incorporation of additional binders like cement and lime) are capable of providing better adhesion in adobe walls than modified ones (with incorporation of binders like cement and lime). More recently, Silva et al. [20] analysed the influence of the composition of unmodified mud grouts on their fresh-state rheology, hardened-state strength, as well as on the adhesion capacity based on three-point bending tests of small-scale unstabilised rammed earth (URE) specimens. The results of these last tests seem to show that the mud grouts employed present good efficiency in terms of strength recover after repair. Nevertheless, the small scale of the specimens did not allow to conclude on the reliability of the repair effectiveness observed.

This paper tries to answer the above referred limitation with basis on an experimental program, which includes the testing of large scale URE specimens. The case of the URE from the region of Alentejo was selected as case study. In addition to the assessment of the mechanical repair effectiveness of different mud grouts, this 
experimental program also aimed at characterizing the mechanical properties of the rammed earth by including axial compression, three-point bending and diagonal compression tests on representative specimens.

\section{EXPERIMENTAL PROGRAM}

The experimental program involved the testing of several URE specimens, which were prepared using a soil from Alentejo with corrected particle size distribution (PSD). This section describes the characterization of the soil used, the manufacturing of the URE specimens and the testing procedures used for the axial compression, three-point bending and diagonal compression tests.

\subsection{Soil}

The soil was collected from Amoreiras-Gare, Odemira (Alentejo) and its suitability for URE construction was assessed with basis on expeditious (sedimentation test, ribbon test, drop test and dry strength test) and laboratory (PSD analysis, Atterberg limits and standard Proctor) tests [21]. In general, the expeditious tests revealed that the clay content of the soil was excessively high for being considered suitable for URE construction. This observation was confirmed by the PSD analysis [22], whose PSD curve is presented in Fig. 1a. This curve is compared with the envelope of suitable soils for rammed earth construction, recommended by Houben and Guillaud [4]. The clay percentage of the soil (about 28\%) is shown to exceed noticeably the maximum recommended value (about 16\%). Table 1 presents the liquid limit (LL), plastic limit (PL) and plastic index (PI) [23], as well as the standard Proctor maximum dry density $\left(\rho_{\text {dmax }}\right)$ and optimum water content (OWC) of the soil

[24]. Houben and Guillaud [4] also proposed an envelope for consistency parameters of soils recommended for rammed earth construction, as depicted in Fig. 1b. Here is shown that this soil fits within recommend values, deeming it as suitable. However, Ciancio et al. (2013) [25] argues that the determination of consistency limits is inaccurate to assess the suitability of a soil for rammed earth construction, since the test is performed on the fraction of particles with size below $0.425 \mathrm{~mm}$, which may not be representative of the behaviour of the full soil. The value obtained for $\rho_{d \max }\left(1830 \mathrm{~kg} / \mathrm{m}^{3}\right)$ seems to be too low for the soil being used in rammed earth construction, which may mean that the correspondent mechanical performance may be insufficient. In general, the characterisation of the soil showed that it is unsuitable for URE. Its high clay content is the main reason leading to this conclusion, meaning that this soil needs PSD correction in order to be used for manufacturing the URE specimens.

The PSD correction of the soil was performed with addition of river sand and gravel (crushed granite). Fig. 1 presents the PSD curves of the corrective materials, as well as the PSD of the corrected soil. The corrected soil 
was composed by $50 \%$ of the original soil, $28 \%$ of river sand and $22 \%$ of gravel (in weight). These percentages were defined by bringing the PSD curve inside the envelope and by taking into account the Fuller curve $(\mathrm{D}=19.1 \mathrm{~mm}$ and $\mathrm{n}=0.25)$ recommended by Huben and Guillaud [4]. This correction reduced the clay content of the soil from $28 \%$ to $14 \%$. The properties of the corrected soil are given in Table 1, which highlights the great improvement of $\rho_{\text {dmax }}$.

Table 1 - Consistency limits and compaction properties of the soil before and after PSD correction.

\begin{tabular}{cccccc}
\hline & LL $(\%)$ & PL $(\%)$ & PI $(\%)$ & $\rho_{\text {dmax }}\left(\mathrm{kg} / \mathrm{m}^{3}\right)$ & OWC $(\%)$ \\
\hline Original soil & 30 & 18 & 12 & 1830 & 13.4 \\
Corrected soil & 23 & 16 & 7 & 2100 & 10.1 \\
\hline
\end{tabular}

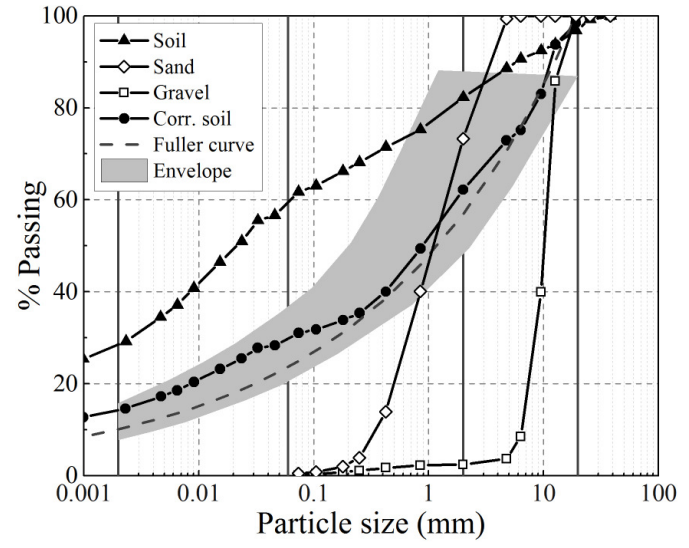

(a)

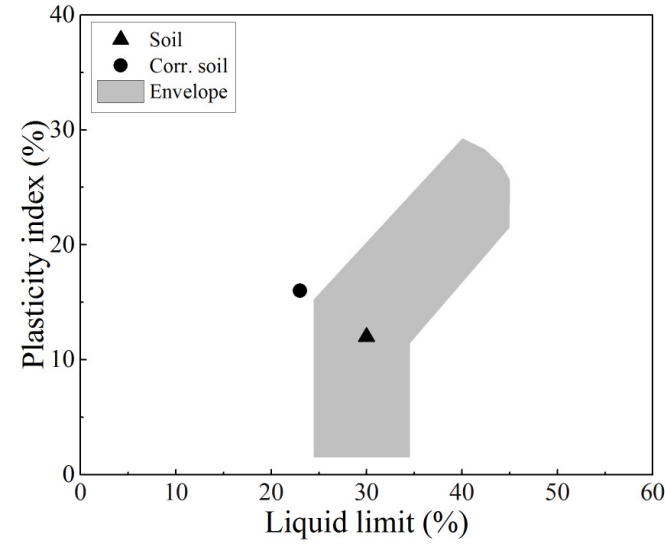

(b)

Fig. 1 - Comparison of the properties of the soils with the recommendations of Houben and Guillaud [4] for: (a) PSD; (b) consistency limits.

\subsection{Preparation of the URE specimens}

The experimental program involved the testing of several URE specimens manufactured with the corrected soil. Six cylinders were prepared for axial compression tests, twelve beams for the three-point bending tests and eleven wallets for the diagonal compression tests.

The cylindrical specimens were compacted in three layers inside a metallic mould with dimensions of $100 \mathrm{~mm}$ diameter and $200 \mathrm{~mm}$ height. An electric rammer was used for this process and the specimens were demolded immediately after compaction (Fig. 2a). The mixture of soil and water of each cylinder was prepared with OWC and hand-mixed, and then was stored inside a plastic bag for about $24 \mathrm{~h}$ before compaction. The compaction process aimed at achieving a density close to $\rho_{\text {dmax }}$.

The beam specimens were compacted inside a metallic mould with dimensions $150 \times 150 \times 600 \mathrm{~mm}^{3}$ in three layers with similar thickness (Fig. 2b). The mixture of soil and water was prepared just before the compaction and the water content was controlled by means of the drop test [26]. The OWC was not used, since the mixtures 
with this water content were apparently excessively dry to initiate the compaction. This situation was probably a consequence of the difficulty in homogenising the large quantity of materials required and of water loss during the manual mixing on the lab floor. Therefore, the compaction process aimed at achieving a wet density close to the maximum wet density obtained from the Proctor test.

The wallets were compacted in nine layers with similar thickness and using a high density plywood formwork with dimensions 550x550x200 $\mathrm{mm}^{3}$ (Fig. 2c). The mixture of soil and water was performed according to a procedure similar to that of the beams. The compaction procedure was also similar and the wallets were also demoulded immediately after compaction.

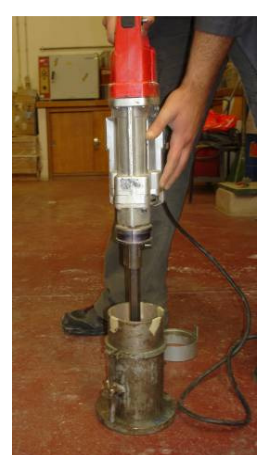

(a)

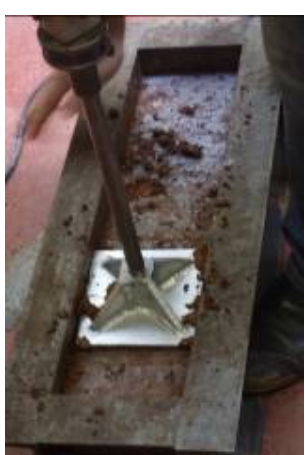

(b)

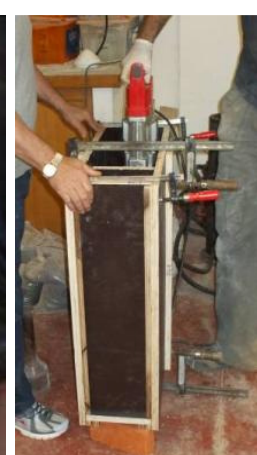

(c)

Fig. 2 - Compaction of the URE specimens: (a) cylinders; (b) beams; (c) wallets.

\subsection{Testing procedures}

The axial compression tests were carried out after the specimens achieved equilibrium water content at $20^{\circ} \mathrm{C}$ temperature and 57.5\% relative humidity (drying period between 27 and 35 days). The equilibrium water content was measured after testing and was found to be in average $1.04 \%$. The vertical deformations at the middle third of each specimen were measured by means of three linear variable displacement transducers (LVDT) radiallydisposed to allow computing the Young's modulus. The load was applied under displacement control at a rate of $0.18 \mathrm{~mm} / \mathrm{min}$. In the day before testing, specimens had their top and bottom capped by a layer of gypsum (see Fig. 3a).

The three-point bending tests were first carried out after drying the specimens for 6 weeks at a room temperature of about $22 \pm 2^{\circ} \mathrm{C}$. The load was applied at middle span and the distance between supports was of about $500 \mathrm{~mm}$ (Fig. 3b). The application of the load was carried out under monotonic displacement control at a rate of $0.06 \mathrm{~mm} / \mathrm{min}$. The testing procedure of the specimens after injection was similar, but these tests were carried out 3 weeks after the repair. The drying was processed under a room temperature similar to that of the specimens before testing. It should be noted that only the maximum force was recorded from these tests. 
The diagonal compression tests were carried out after drying the wallets for 12 weeks at a room temperature of about $22 \pm 2^{\circ} \mathrm{C}$. The procedure used was similar to that of ASTM E 519 [27]. The supports were made of steel, with a width of about $100 \mathrm{~mm}$, and the contact with the specimens was rectified by means of neoprene rubbers introduced between specimens and supports. The load was applied under monotonic displacement control at a rate of $0.12 \mathrm{~mm} / \mathrm{min}$ and the vertical and horizontal displacements were measured in both faces of the wallets, resorting to LVDTs attached to the middle third of each diagonal (see Fig. 3c). The same procedure was used for the wallets tested after repair with injection of mud grouts.

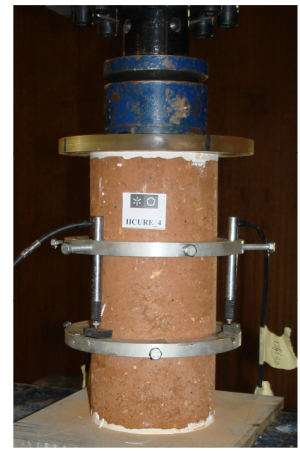

(a)

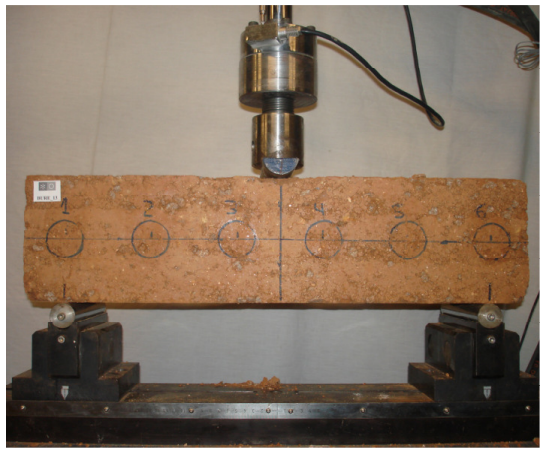

(b)

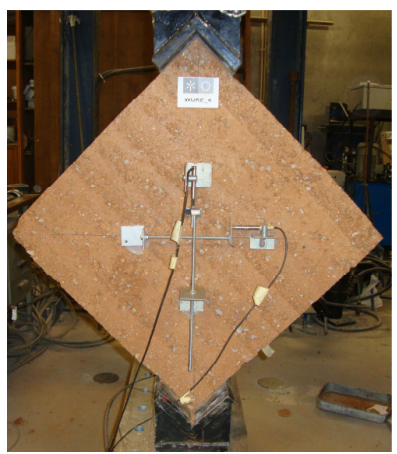

(c)

Fig. 3 - Testing setups: (a) axial compression; (b) three-point bending; (c) diagonal compression.

\section{REPAIR OF THE SPECIMENS}

The URE beams and wallets were repaired by means of injection of mud grouts after being tested once. This section describes the mud grouts used in the repair of the specimens, as well as the repairing procedures.

\subsection{Mud grouts}

Three unmodified (without addition of typical mineral binders) mud grouts were used in the repair of the URE specimens. Grout A was constituted by kaolin powder (Mibal-A) and limestone powder (200-OU), while grout B and $\mathrm{C}$ were constituted by sieved soil (the same soil used in the manufacture of the URE specimens) with maximum particle size of about $0.18 \mathrm{~mm}(\mathrm{~S} \# 80)$ and limestone powder (Micro 200-OU) in different proportions. The composition of the grouts is given in Table 2 and the respective PSD is depicted in Fig. 4. Sodium hexametaphosphate (HMP, expressed as percentage of the solid phase) was used to improve the fluidity of all grouts, while keeping their W/S (water/solids) ratio low. HMP is typically used as a dispersant/deflocculant for clay suspensions in several industries (e.g. ceramic and paper processing), where its action is achieved by means of a concerted mechanism [28]: (i) increase in the overall negative surface charge by the adsorption of anionic HMP polymeric chains onto the surface of the clay particles; (ii) stabilisation caused by the steric hindrance effect of the adsorbed HMP chains; (iii) complexing of the dissolved alkaline-earth cations and replacing them 
by lower valence $\mathrm{Na}^{+}$cations, which increases the thickness of the electric double layers of the clay particles surfaces. The effects of the addition of HMP in mud grouts are reported elsewhere [20].

The use of grout A aimed at testing the possibility of using mud grouts resulting from the blend of commercial materials [29], while grouts B and C aimed at promoting maximum compatibility by incorporating the original soil used to manufacture the specimens. It should be noted that the PSD of all grouts was similar, nevertheless they presented different percentages of clay, namely $18 \%, 21 \%$ and $25 \%$ for gout A, B and C, respectively. The properties of the grouts are given in Table 3, in terms of flow time of $1 \mathrm{dm}^{3}$ of grout [30], dry density $\left(\rho_{d}\right)$, volumetric shrinkage $\left(S_{v}\right)$, flexural and compressive strengths [31], see also [21] for further details. It should be noted that the higher percentage of clay of grout $\mathrm{C}$ resulted in higher mechanical properties than those of gout B, while the fluidity was similar.

Table 2 - Composition of the unmodified mud grouts.

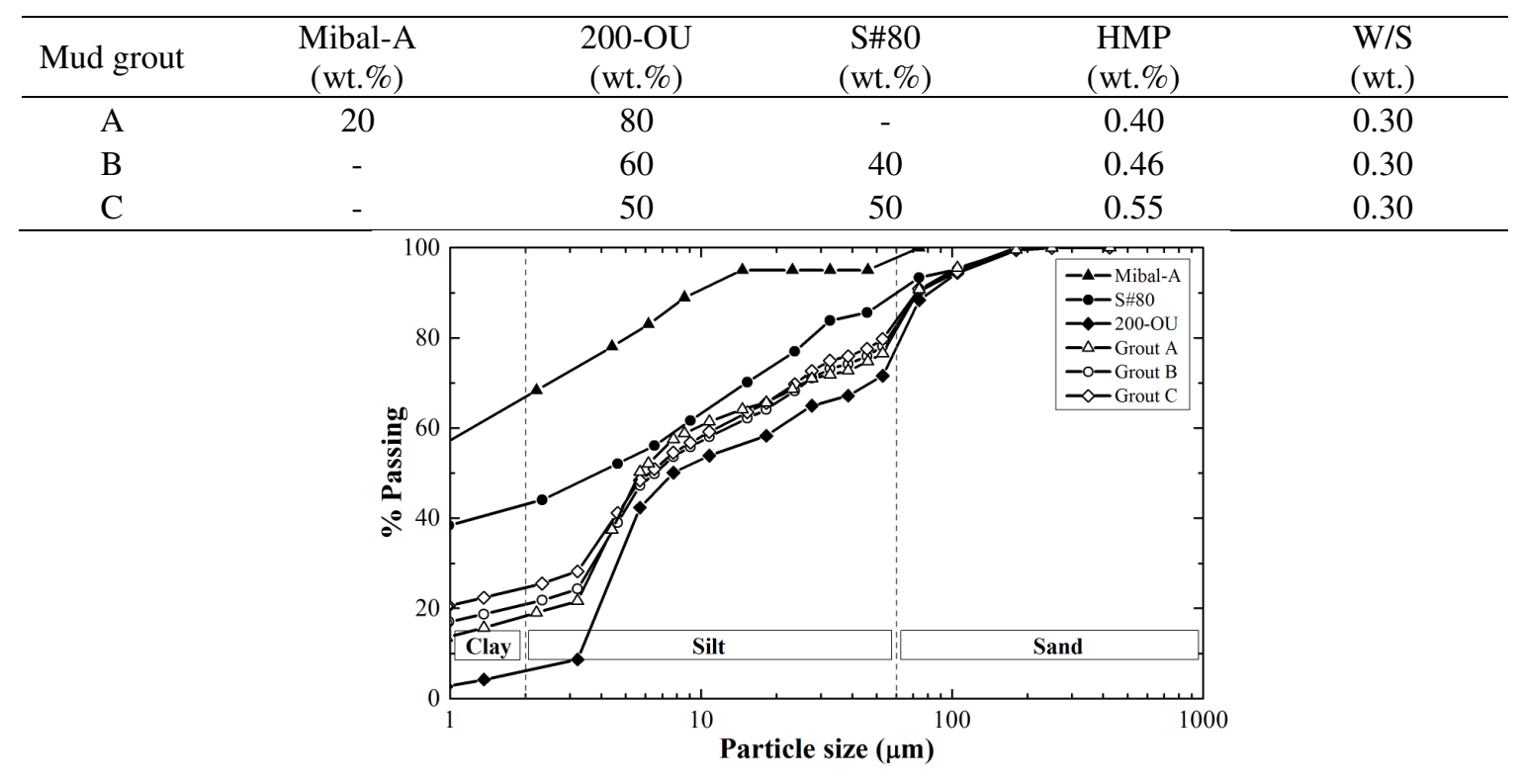

Fig. 4 - PSD of the mud grouts.

Table 3 - Properties of the unmodified mud grouts.

\begin{tabular}{cccccc}
\hline Mud grout & $\begin{array}{c}\text { Flow time } \\
(\mathrm{s})\end{array}$ & $\begin{array}{c}\rho_{d} \\
\left(\mathrm{~kg} / \mathrm{m}^{3}\right)\end{array}$ & $\begin{array}{c}S_{v} \\
(\%)\end{array}$ & $\begin{array}{c}f_{b} \\
\left(\mathrm{~N} / \mathrm{mm}^{2}\right)\end{array}$ & $\begin{array}{c}f_{c} \\
\left(\mathrm{~N} / \mathrm{mm}^{2}\right)\end{array}$ \\
\hline A & 85.9 & 1802 & 12.7 & 0.62 & 1.48 \\
B & 36.5 & 1789 & 13.2 & 0.92 & 2.44 \\
C & 37.0 & 1814 & 15.6 & 1.15 & 3.47 \\
\hline
\end{tabular}

\subsection{Repair of the beam specimens}

The two parts of the specimens resulting from the initial three-point bending tests were bonded together using the mud grouts, which were injected in the gap between them. The base and sides of the specimens were sealed, 
but the rising of the grouts could be visualised from the sides through the Plexiglas plates (Fig. 5a). The specimens' parts were positioned in such a way that the gap between them $\left(d_{c r}\right)$ was of about $2 \mathrm{~mm}$ or $8 \mathrm{~mm}$, totalizing 6 specimens for each case. The injection was performed using a $100 \mathrm{ml}$ syringe coupled to a $4 \mathrm{~mm}$ diameter tube installed at the bottom of one of the Plexiglas plates. For each set of six specimens with the same $d_{c r}$, three specimens were injected with grout A and other three with grout B.

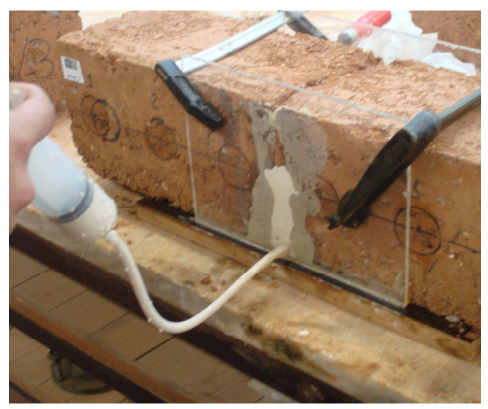

(a)

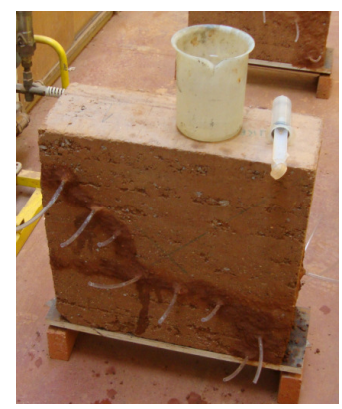

(b)

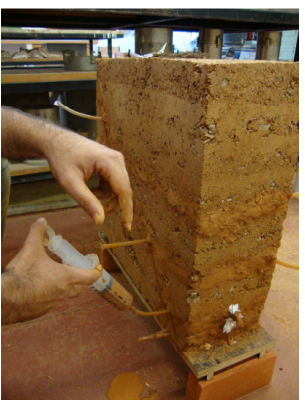

(c)

Fig. 5 - Repair of the URE specimens: (a) injection of the beams; (b) sealing of the cracks in a wallet; (c) injection of the wallet.

\subsection{Repair of the wallets specimens}

The failure of the wallets split them in some parts, which were removed from the testing apparatus and remounted together on a plywood board. Loose debris were removed from the failure surfaces before remounting the wallets. The remounting was performed by assembling piece by piece, and when a specimen presented high instability, it was tied by means of two plywood boards. The assembling was carried out with the aid of an earth mortar to seal the cracks, prepared with the original soil sieved to remove the particles larger than $4.75 \mathrm{~mm}$. Flexible plastic tubes with $6 \mathrm{~mm}$ diameter were installed in one of the sides of the specimens. The injection tubes were installed first in the intersection of cracks and then along the cracks, in such way that the spacing between injection tubes was less than $100 \mathrm{~mm}$. In the case of horizontal cracks, additional injection tubes were installed in the other side of the wallets to just facilitate the air evacuation (see Fig. 5b).

Before injecting the wallets with the mud grout, $100 \mathrm{ml}$ of water was injected in each injection tube, using the $100 \mathrm{ml}$ capacity syringe. This procedure intended to mitigate the water sorption by the wallets and to check if the injection tubes were active. The wallets were injected with the mud grouts one hour after water injection, using the aforementioned $100 \mathrm{ml}$ syringe. The injection started by the lowest tube and progressed up to the top of the wallet. The tube being injected was sealed once the grout leaked from the next injection tube (normally the one immediately above). The injection was then carried out from the leaking tube, and so on (see Fig. 5c). The occurrence of leakage from the sealing mortar was not very frequent and was easily solved by pressing soft paper against the leaking crack. Five wallets were repaired with grout B and other six with grout C. 


\section{RESULTS AND DISCUSSION}

\subsection{Axial compression}

The stress-strain curves of the URE specimens tested under axial compression are presented in Fig. 6, where a high non-linear behaviour can be observed. The average compressive strength $\left(f_{c}\right)$ was of about $1.26 \mathrm{~N} / \mathrm{mm}^{2}$, with a corresponding coefficient of variation $(\mathrm{CoV})$ of about $4 \%$. The lowest value obtained was of about $1.20 \mathrm{~N} / \mathrm{mm}^{2}$, meaning that the compressive strength obtained deems with the minimum requirements of NZS 4298 [26] for standard grade rammed earth constructions, where the least value of a set of specimens must be higher than $1.14 \mathrm{~N} / \mathrm{mm}^{2}$ (after considering the aspect ratio of the specimens). The average Young's modulus $\left(E_{0}\right)$, computed between $5 \%$ and $30 \%$ of the respective compressive strength by linear fitting, was of about $1034 \mathrm{~N} / \mathrm{mm}^{2}$, where variability was found to be high, with a CoV of about $23 \%$. Despite the manufacturing of the specimens was controlled in lab, $E_{0}$ was shown to be more sensitive than $f_{c}$ to any variability existing between the testing of the specimens. Moreover, the average $E_{0}$ is found to be of about 820 times the average $f_{c}$, which is a rather high relation if one takes into account that NZS 4297 [32] estimates this parameter as $300 f_{c}$, meaning that a careful use of this last relation should be taken for other cases.

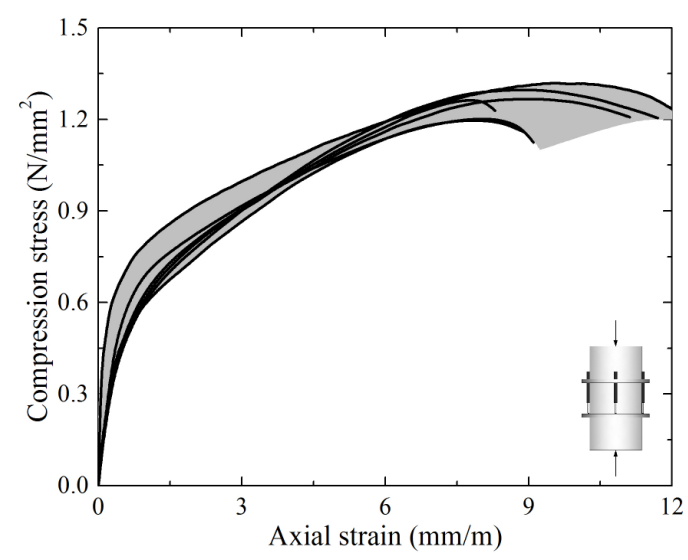

Fig. 6 - Stress-strain curves of the URE specimens tested under axial compression.

\subsection{Three-point bending}

The Plexiglas plates allowed to visualise the injection of mud grouts A and B, and also allowed to assess their injectability through the two types of cracks injected. With this respect, none of the grouts showed difficulty in penetrating through the two types of cracks. This observation means that the injection of cracks with at least $2 \mathrm{~mm}$ thickness is possible for the grouts used providing that the rammed earth does not present excessive moisture sorption, for instance caused by adverse ambient conditions.

Fig. 7a summarises the results of the three-point bending tests in terms of average initial flexural strength, flexural strength after grout injection and the recovery ratio. On average terms, the flexural strength obtained for 
the URE beams was of about $0.22 \mathrm{~N} / \mathrm{mm}^{2}$, which corresponds to about $18 \%$ of the average compressive strength. However, it should be noted that the requirement of NZS 4298 [26] for standard grade rammed earth constructions is not respected in terms of flexural strength (minimum of $0.25 \mathrm{~N} / \mathrm{mm}^{2}$ ), because the lowest value obtained from the set of twelve specimens tested was of about $0.17 \mathrm{~N} / \mathrm{mm}^{2}$. With respect to the repair effectiveness of the injection, Grout A showed poor recovery ratio for both tested crack widths, where for $d_{c r}=2 \mathrm{~mm}$ the average recovery ratio was of about $26 \%$, while that for $d_{c r}=8 \mathrm{~mm}$ was of about $17 \%$. Grout B, on the other hand, showed a very satisfactory adhesion capacity by presenting an average recovery ratio of about $55 \%$ for $d_{c r}=2 \mathrm{~mm}$ and of about $74 \%$ for $d_{c r}=8 \mathrm{~mm}$. Even though grout B is stronger than grout A, this fact does not justify the unsatisfactory results obtained for grout A. Probably this difference can be explained by differences in their clay fraction, where that of grout B is similar to that of the beam specimens, since it is composed by the respective soil.

The failure of the specimens repaired with grout A occurred mostly at the interface of mud grout/rammed earth (Fig. 7b), but there were cases where it occurred inside the grout. The first situation means that the adhesion capacity of the grout was the limiting property, while in the second situation the tensile strength of the mud grout was the limiting property. However, the flexural strength of grout A fairly exceeds the flexural strength of the rammed earth specimens in about 2.8 times, whereby failure through the grout should not be happening. The occurrence of cracking due to shrinkage may explain a strength reduction of the grout and thus its poor performance for the situations imparting this failure mode. The failure of the specimens repaired with grout B occurred mostly by failure of the rammed earth (Fig. 7c), mixed in some cases with failure at the interface mud grout/rammed earth. The occurrence of the first failure mode means that grout B presents a great adhesion capacity, which theoretically indicates the total recovery of the flexural strength of the specimens. However and despite the satisfactory recovery ratio achieved by this mud grout, all specimens were distant from achieving $100 \%$ recovery. This aspect is most probably related with the weakening of the rammed earth material nearby the crack during the first test.

These results seem to encourage using the same soil used in the construction to compose a mud grout in a repair intervention. Moreover, the unsatisfactory result of grout A justifies the decision of not considering it in the repair of the wallets. 


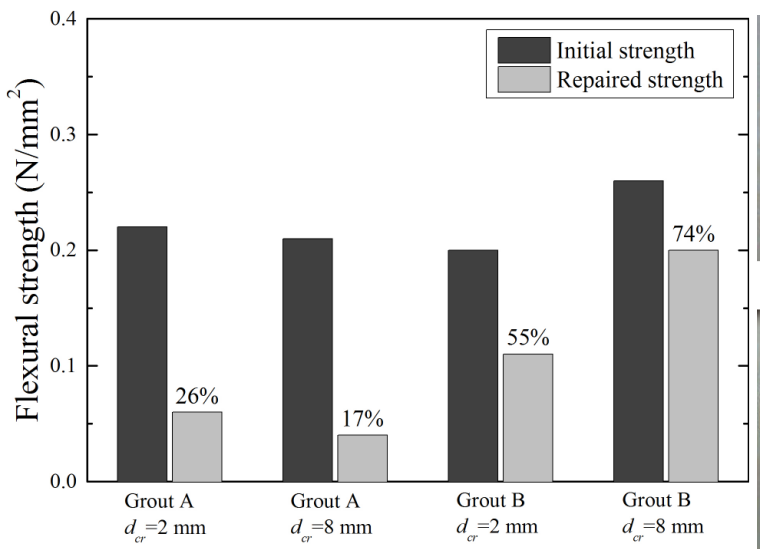

(a)

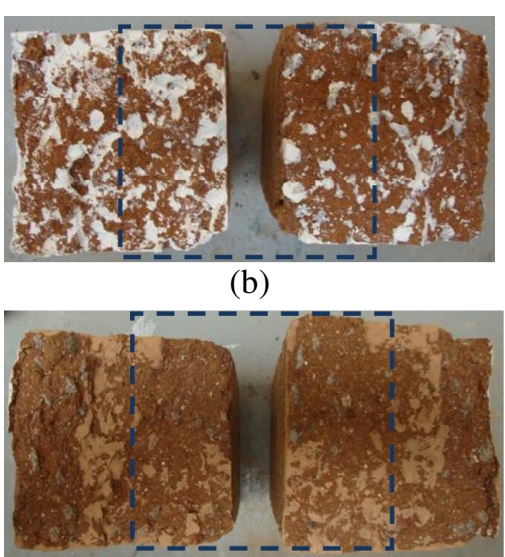

(c)

Fig. 7 - Results of the three-point bending tests of the rammed earth specimens: (a) injection recovery ratio; (b) failure mode of a beam injected with grout A (failure occurring mostly at the interface mud grout/rammed earth); (c) failure mode of a beam injected with grout B (failure occurring partially inside the rammed earth and at the interface mud grout/rammed earth).

\subsection{Diagonal compression}

Table 4 and Table 5 summarise the results of the diagonal compression tests carried out on the wallets repaired with grouts B and $\mathrm{C}$, respectively, namely in terms of dry density $\left(\rho_{d}\right)$, shear strength $\left(f_{s i}\right)$ and shear modulus $\left(G_{0 i}\right)$ in the first test, shear strength $\left(f_{s g}\right)$ and shear modulus $\left(G_{0 g}\right)$ in the second test (after repair by means of grout injection); shear strength recovery ratio $\left(f_{s g} / f_{s i}\right)$ and shear modulus recovery ratio $\left(G_{g i} / G_{0 i}\right)$. The shear moduli were computed between $5 \%$ and $30 \%$ of the shear strength of the respective specimen.

The average shear strength in the first test (prior to repair) for both sets of wallets was of about $0.15 \mathrm{~N} / \mathrm{mm}^{2}$, but this parameter presents some variability despite the low variability of $\rho_{d}$. This average shear strength value is considerably higher than that reported by Lacouture et al. [33] for URE (about $0.04 \mathrm{~N} / \mathrm{mm}^{2}$ ), which also reported a lower compressive strength $\left(0.55 \mathrm{~N} / \mathrm{mm}^{2}\right)$. The obtained average shear strength here reported for URE is significantly higher than those reported by Lacouture et al. [33] and Varum et al. [34] for adobe masonry, namely between $0.02 \mathrm{~N} / \mathrm{mm}^{2}$ and $0.03 \mathrm{~N} / \mathrm{mm}^{2}$. This low performance of adobe masonry can be explained by the fact that mortar joints constitute preferential failure surfaces, which are not present in the case of rammed earth.

Table 4 - Results of the diagonal compression tests carried on the wallets repaired with grout B.

\begin{tabular}{cccccccc}
\hline Wallet & $\begin{array}{c}\rho_{d} \\
\left(\mathrm{~kg} / \mathrm{m}^{3}\right)\end{array}$ & $\begin{array}{c}f_{s i} \\
\left(\mathrm{~N} / \mathrm{mm}^{2}\right)\end{array}$ & $\begin{array}{c}f_{s g} \\
\left(\mathrm{~N} / \mathrm{mm}^{2}\right)\end{array}$ & $\begin{array}{c}f_{s g} / f_{s i} \\
(\%)\end{array}$ & $\begin{array}{c}G_{0 i} \\
\left(\mathrm{~N} / \mathrm{mm}^{2}\right)\end{array}$ & $\begin{array}{c}G_{0 g} \\
\left(\mathrm{~N} / \mathrm{mm}^{2}\right)\end{array}$ & $\begin{array}{c}G_{0 g} / G_{0 i} \\
(\%)\end{array}$ \\
\hline WURE_1 & 2020 & 0.17 & 0.07 & 39 & 659 & 67 & 10 \\
WURE_2 & 2060 & 0.16 & 0.15 & 93 & 705 & 53 & 8 \\
WURE_3 & 2040 & 0.13 & 0.06 & 43 & 413 & 47 & 11 \\
WURE_4 & 2030 & 0.14 & 0.09 & 68 & 341 & 54 & 16 \\
WURE_11 & 2040 & 0.14 & 0.12 & 89 & 732 & 142 & 19 \\
\hline Average (CoV) & $2040(1 \%)$ & $0.15(10 \%)$ & $0.10(40 \%)$ & $66(38 \%)$ & $570(32 \%)$ & $73(54 \%)$ & $13(37 \%)$ \\
\hline
\end{tabular}


Table 5 - Results of the diagonal compression tests carried on the wallets repaired with grout $\mathrm{C}$.

\begin{tabular}{cccccccc}
\hline Wallet & $\begin{array}{c}\rho_{d} \\
\left(\mathrm{~kg} / \mathrm{m}^{3}\right)\end{array}$ & $\begin{array}{c}f_{s i} \\
\left(\mathrm{~N} / \mathrm{mm}^{2}\right)\end{array}$ & $\begin{array}{c}f_{s g} \\
\left(\mathrm{~N} / \mathrm{mm}^{2}\right)\end{array}$ & $\begin{array}{c}f_{s g} / f_{s i} \\
(\%)\end{array}$ & $\begin{array}{c}G_{0 i} \\
\left(\mathrm{~N} / \mathrm{mm}^{2}\right)\end{array}$ & $\begin{array}{c}G_{0 g} \\
\left(\mathrm{~N} / \mathrm{mm}^{2}\right)\end{array}$ & $\begin{array}{c}G_{0 g} / G_{0 i} \\
(\%)\end{array}$ \\
\hline WURE_5 & 2010 & 0.11 & 0.09 & 77 & 464 & 89 & 19 \\
WURE_6 & 1970 & 0.14 & 0.07 & 52 & 646 & 33 & 5 \\
WURE_7 & 2020 & 0.17 & 0.09 & 55 & 640 & 29 & 5 \\
WURE_8 & 2030 & 0.13 & 0.09 & 68 & 1036 & 73 & 7 \\
WURE_9 & 2020 & 0.14 & 0.07 & 54 & 807 & 66 & 8 \\
WURE_10 & 2040 & 0.19 & 0.09 & 46 & 661 & 45 & 7 \\
\hline Average (CoV) & $2010(1 \%)$ & $0.15(19 \%)$ & $0.08(10 \%)$ & $59(20 \%)$ & $709(27 \%)$ & $56(43 \%)$ & $8(64 \%)$ \\
\hline
\end{tabular}

The average shear strength of the wallets obtained from the second test (repaired specimens) is of about $0.10 \mathrm{~N} / \mathrm{mm}^{2}$ and $0.08 \mathrm{~N} / \mathrm{mm}^{2}$ for the case of the set of wallets repaired with grout $\mathrm{B}$ and that repaired with grout C, respectively. These values correspond to an average shear strength recovery ratio of about $66 \%$ and $59 \%$, respectively, which are percentages somehow distant from the complete shear strength recovery (100\%), meaning that this goal is very difficult to achieve in practice. In fact, wallets present damage at the micro level (eg.: micro-cracking) that cannot be repaired by injection. Despite that, both grouts presented satisfactory performance regarding the adhesion capacity. Another important observation to be highlighted is that grout $\mathrm{C}$ promoted a recovery ratio slightly lower than grout B, despite its higher strength. In fact, the performance of both grouts is similar, indicating that a higher clay percentage may not mean a higher adhesion capacity and that the repair capacity may have been limited by the damage introduced during the first test.

The shear stress-strain curves of the wallets before and after injection are presented in Fig. 8. With respect to the behaviour of both sets of wallets before repair, it is observed that most of the wallets present an early peak shear stress, after which the shear strain has a fast increase. This early peak shear stress is believed to be mainly related to cohesion (i.e. to the binding capacity) promoted by the clay fraction. After this point, the contribution of the cohesion is lost and the shear behaviour of the wallets relies only on the friction and interlocking capacity of the coarse aggregates. Moreover, most of the wallets present hardening behaviour after the peak stress, which can be explained by superior interlocking occurring in these wallets. Another important contribution of the friction and interlocking mechanisms to the shear behaviour of the wallets is the large shear deformation capacity, thus ductility, presented by all wallets (except for WURE_4). This feature is important for a rammed earth construction in the case of a seismic event, since it is expected to contribute for the energy dissipation.

With respect to the shear stress-strain curves of the wallets in the second test, a substantial decrease in stiffness relative to the first test is observed, no matter the grout used. The average $G_{0 g}$ corresponds to an overall decrease of about one order of magnitude with respect to $G_{0 i}$. This important decrease may be explained by less efficient 
interlocking and friction mechanisms in the wallets after repair. In fact, interlocking prior to repair was provided by coarse aggregates, which were then lost in the reassembling of the specimens and not reintroduced by the injection. Therefore, this potential failure surface had its interlocking and friction mechanisms clearly lowered. Moreover, the lower interlocking and friction of the repaired wallets can also be pointed out as a reason to explain a shear strength recovery that was shown to be relatively inferior to total recovery.

The failure of the wallets in the first test occurred as a consequence of the formation of a main crack or set of cracks with a predominant diagonal orientation, crossing the entire specimen (Fig. 9a and b). The formation of these cracks was observed visually to start just before the peak load, at the middle of the specimens, and then developed toward the top and bottom supports. Some cracks occurred also at the interface between layers, which propagated from the edges to the interior of the wallet. This failure mode means that these interfaces constitute weak surfaces when the rammed earth is subjected to tension and/or shear. It should be noted that the onset formation of these cracks occurred just before the specimens achieving the maximum load, meaning that maybe they have little importance regarding the shear behaviour of the wallets.

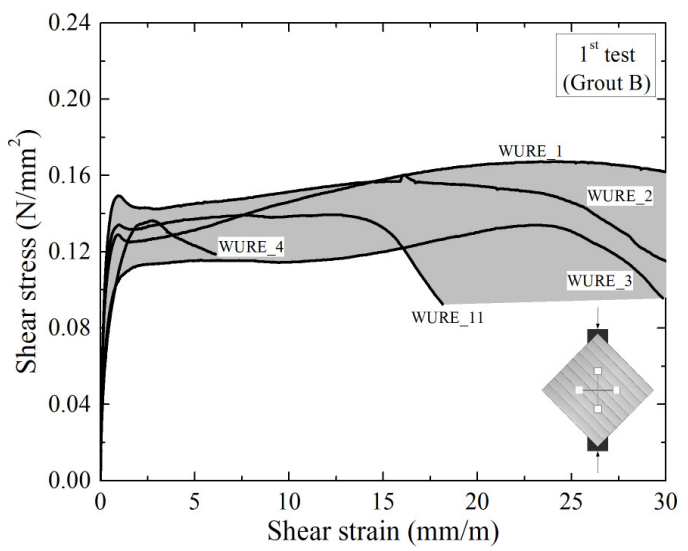

(a)

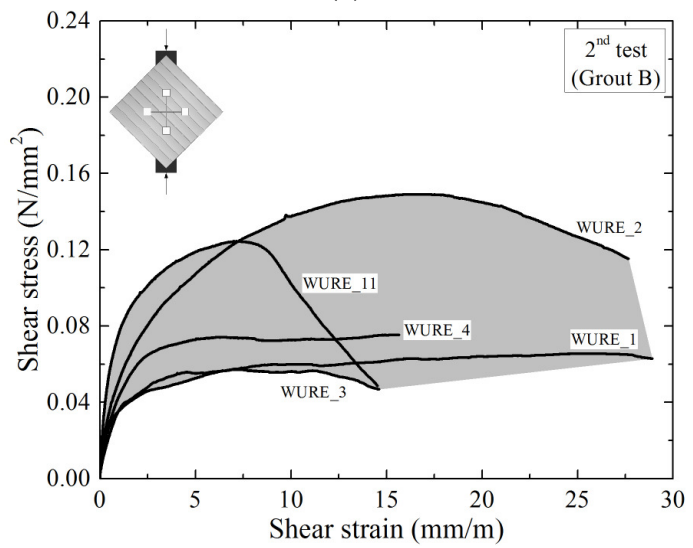

(c)

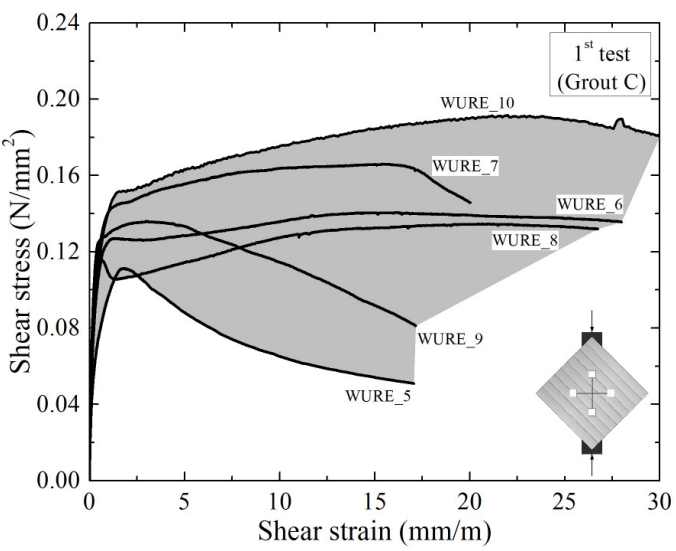

(b)

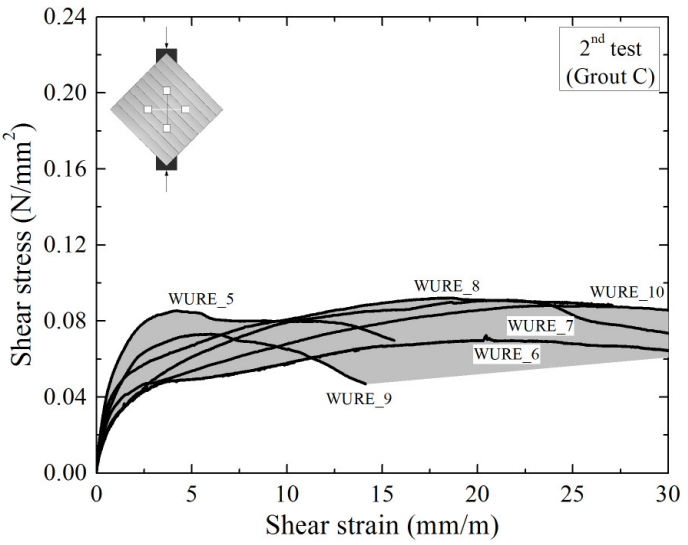

(d)

Fig. 8 - Shear stress-strain curves of the wallets: (a) first test of the set repaired with grout B; (b) first test of the set repaired with grout $\mathrm{C}$; (c) second test of the set repaired with grout B; (d) second test of the set repaired with grout C. 
In general, the crack pattern of the wallets in the second test followed that of the first test, confirming that the initial cracks, once repaired, still constitute preferential failure surfaces (see Fig. 9). This behaviour is a consequence of the impossibility of the mud grout in repairing the micro-damage in the rammed earth material at the vicinity of the repaired cracks, and of the loss of interlocking capacity, as discussed previously.

The observation of the failure surfaces after the second test of the wallets allowed assessing the great difficulty in injecting the cracks at the interfaces between layers, since some of these horizontal cracks were only partially filled. This situation occurred due to difficulties in evacuating the air from the cracks, despite the care taken. Small gaps (2-6 cm of maximum size) in the hardened grout were also detected, which are probably associated to flowing of the grout to unfilled horizontal cracks, as they appear immediately above them (see Fig. 10a). The presence of these gaps probably contributed also for a lower performance of wallets after repair, since the failure surfaces tended to cross them. Regarding the minimum width of the injected cracks, it was observed to be of about $1 \mathrm{~mm}$ (see Fig. 10b). However, this observation does not imply that thinner cracks cannot be injected by the tested grouts. According to Miltiadou [35], only cracks with width larger than three times the maximum particle size of the grout are injectable, which in the case of the tested grouts corresponds to $0.54 \mathrm{~mm}(3 \mathrm{x} 0.180$ $\mathrm{mm})$. This value shows a good penetrability capacity of the mud grouts used.
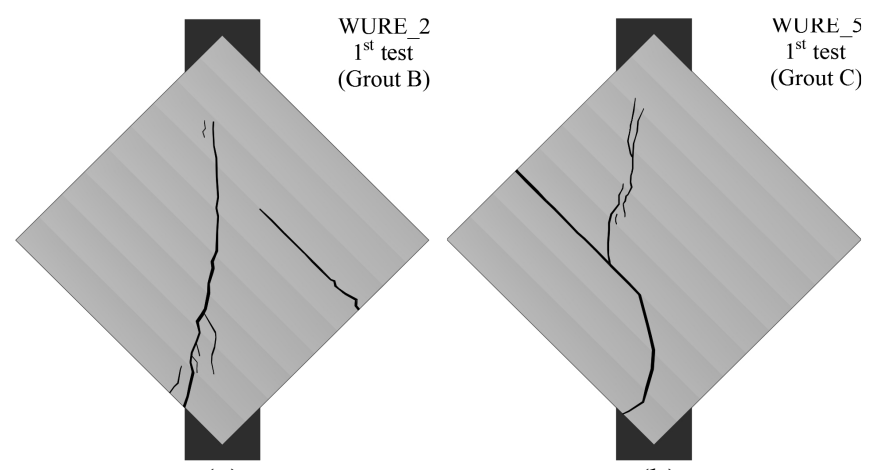

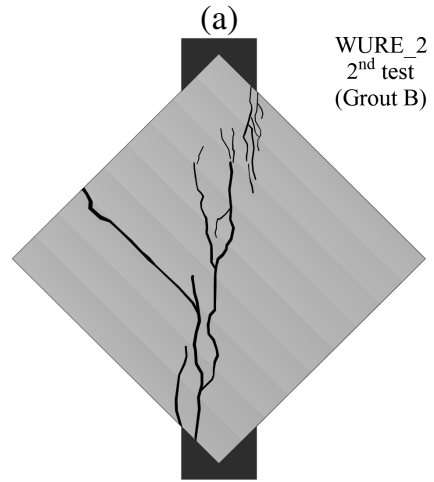

(c)

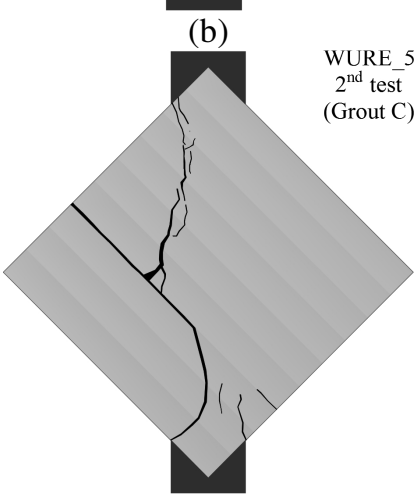

(d)

Fig. 9 - Failure mode: (a) WURE_2 after the first test; (b) WURE_5 after the first test; (c) WURE_2 after the second test; (d) WURE_5 after the second test. 


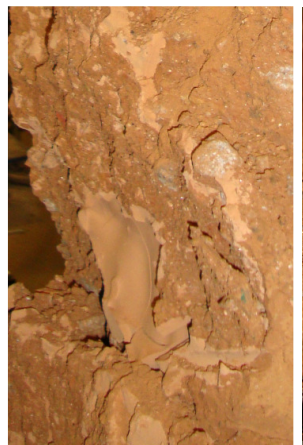

(a)

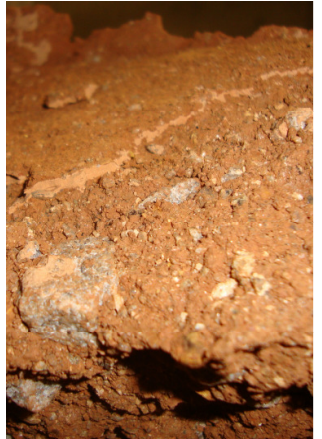

(b)

Fig. 10 - Failure surface of the wallets after the second test: (a) presence of a gap in the grout (WURE_1); (b) injected crack with about $1 \mathrm{~mm}$ width (WURE_3).

\section{CONCLUSIONS}

This paper deals with mechanical effectiveness of the repair of cracks in URE walls by means of injection of unmodified mud grouts. An experimental program was carried out and the results obtained allowed to point out the following conclusions:

- The shear behaviour of URE walls seems to result from the contribution of the binding promoted by the clay fraction of the soil and from the friction and interlocking promoted by the coarse aggregates. The friction and interlocking seems to control the non-linear behaviour of URE and to promote a significant shear deformation capacity, which is expected to have an important role on the energy dissipation of a URE wall in the case of an earthquake.

- The injectability properties (fluidity, penetrability and water retention capacity) of the mud grouts used seemed to be adequate for injecting completely the range of crack widths visible in the URE specimens repaired. Nevertheless, the difficulties of injecting completely the horizontal cracks of the wallets showed that special care must be taken with air evacuation in the injection of this type of crack in a URE wall.

- The repair effectiveness achieved by grout A in the URE beam specimens was poor while that achieved by grout B was acceptable. This result seems to encourage using the same soil used in the construction to compose a mud grout in a repair intervention, both for fulfilling compatibility and adhesion demands. Furthermore, the development of a ready-mix mud grout, as a general solution, seems to be somehow problematic.

- Grouts B and C presented a similar and satisfactory recovery capacity of the shear strength of the wallets, but still distant from the complete recovery. The repair capacity of grout injection alone is limited by microdamage at material in the vicinity of the crack. 
- The repair by means of injection seems to be incapable of re-establishing the initial shear stiffness of a URE wall, which appears to be a consequence of the incapacity of the mud grout in recovering the interlocking promoted by the coarse aggregates at the crack.

\section{ACKNOWLEDGEMENTS}

This work was partly financed by FEDER funds through the Competitivity Factors Operational Programme COMPETE and by national funds through FCT - Foundation for Science and Technology within the scope of projects POCI-01-0145-FEDER-007633 and POCI-01-0145-FEDER-016737 (PTDC/ECM-EST/2777/2014). The first author would also like to acknowledge FCT for the Post-doc grant SFRH/BPD/97082/2013.

\section{REFERENCES}

[1] Rocha M. (2005) Rammed earth in traditional architecture: construction techniques. In Earth architecture in Portugal. Argumentum, Lisbon, Portugal, pp. 21-26.

[2] Correia M. (2007) Rammed Earth in Alentejo. Argumentum, Lisbon.

[3] Fernandes M. (2008) Rammed earth in the World. In proc. of Seminário de Construção e Recuperação de Edifícios em Taipa, Almodôvar, Portugal. (in Portuguese)

[4] Houben H., Guillaud H. (2008) Earth Construction: A Comprehensive Guide. $3^{\text {rd }}$ Edition, CRATerre EAG, Intermediate Technology Publication, London, UK.

[5] Jaquin P.A., Augarde C.E., Gerrard C.M. (2008) Chronological Description of the Spatial Development of Rammed Earth Techniques. International Journal of Architectural Heritage, 2(4), pp. 377-400.

[6] Braga A.M, Estêvão J.M.C (2012) Difficulties associated with the rehabilitation the rammed earth built heritage in Algarve. In proc. of Congresso da Construção 2012, 18-20 December, Coimbra, Portugal. (in Portuguese)

[7] Correia, M. Islamic fortresses in military rammed earth, Pedra \& Cal, 24 (2004), pp. 16. (in Portuguese)

[8] Oliveira D.V., Silva R.A., Lourenço P.B., Schueremans L. (2010) The rammed earth constructions and the earthquakes. In proc. of Congresso Nacional de Sismologia e Engenharia. SÍSMICA 2010, 20-23 October; Aveiro, Portugal. (in Portuguese)

[9] Silva R.A., Jaquin P., Oliveira D.V., Miranda T., Schueremans L., Cristelo N. (2014) Conservation and new construction solutions in rammed earth. Structural Rehabilitation of Ancient Buildings, A. Costa; J. Miranda; H. Varum (Eds), Springer, pp. 77-108. ISBN 978-3-642-39685-4.

[10] Warren J. (1999) Conservation of Earth Structures. Butterworth Heinemann, Bath, UK. 
[11] Cabral M.I. (2008) CAAAP - Ambient certification of architecture in protected areas. In proc. of Congress of Innovation on Sustainable Construction, 22-25 October, Portugal. (in Portuguese)

[12] Keefe L. (2005) Earth Building: Methods and materials, repair and conservation. Taylor \& Francis: London.

[13] Pearson G.T. (1997) Conservation of Clay and Chalk Buildings. Shaftsbury, Donhead Publishing Ltd.

[14] Getty (2007) Interdisciplinary Experts Meeting on Grouting Repairs for Large-scale Structural Cracks in Historic Earthen Buildings in Seismic Areas. The Getty Conservation Institute.

[15] Roselund N. (1990) Repair of cracked walls by injection of modified mud. In proceedings of the 6th International Conference on the Conservation of Earthen Architecture: Adobe 90 Preprints, Las Cruces, New Mexico, pp. 336-341.

[16] Jäger W., Fuchs C. (2008) Reconstruction of the Sistani House at Bam Citadel after the collapse due to the earthquake 2003. In proc. of VI International Conference on Structural Analysis of Historic Constructions, D’Ayala D. and Fodde E. Eds., Vol. 2, Bath, UK, pp. 1181-1187.

[17] Müller U., Miccoli L., Fontana P. (2016) Development of a lime based grout for cracks repair in earthen constructions. Construction and Building Materials 2016, 110, pp. 323-332.

[18] Vargas J., Blondet M., Cancino C., Ginocchio F., Iwaki C., Morales K. (2008) Experimental results on the use of mud-based grouts to repair seismic cracks on adobe walls. In proceedings of the VI International Conference on Structural Analysis of Historic Constructions, D’Ayala D. and Fodde E. Eds., Bath, UK, pp. 1095-1099.

[19] On Yee L. (2009) Study of earth-grout mixtures for rehabilitation. MSc Thesis, University of Minho, Guimarães, Portugal.

[20] Silva R.A., Schueremans L., Oliveira D.V., Dekoning K., Gyssels T. (2012) On the development of unmodified mud grouts for repairing earth constructions: rheology, strength and adhesion. Materials and Structures 2012, 45 (10), pp. 1497-1512.

[21] Silva R.A. (2013) Repair of earth constructions by means of grout injection. PhD thesis, University of Minho / KUleuven, Guimarães, Portugal.

[22] LNEC (1966) E196: Soils: Particle size distribution analysis. Laboratório Nacional de Engenharia Civil: Lisbon, Portugal. (in Portuguese)

[23] LNEC (1969) NP 143: Soils: determination of the consistency limits. Laboratório Nacional de Engenharia Civil, Lisbon, Portugal. (in Portuguese) 
[24] LNEC (1967) E197: Compaction test. Laboratório Nacional de Engenharia Civil, Lisbon; Portugal. (in Portuguese)

[25] Ciancio D., Jaquin P., Walker P. (2013) Advances on the assessment of soil suitability for rammed earth. Construction and Building Materials 2013, 42, pp. 40-47.

[26] NZS (1998) New Zealand Standard 4298: 1998, Materials and workmanship for earth building. Standards New Zealand, Wellington.

[27] ASTM (2002) ASTM E 519: Standard Test Method for Diagonal Tension (Shear) in Masonry Assemblages. American Society for Testing and Materials: West Conshohocken.

[28] Andreola F., Castellini E., Ferreira J.M.F., Olhero S., Romagnoli M. (2006) Effect of sodium hexametaphosphate and ageing on the rheological behaviour of kaolin dispersions, Applied Clay Science, 31, pp. 56-64.

[29] Martins C. (2012) Repair of rammed earth constructions by means of grout injection. Msc Thesis, University of Minho, Portugal. (in Portuguese)

[30] ASTM (1994) ASTM C 939-94: Standard test method for flow of grout for preplaced-aggregate concrete (flow cone method). American Society for Testing and Materials: West Conshohocken.

[31] CEN (1999) EN 1015-11: 1999: Methods of test for mortar for masonry - Part 11: Determination of flexural and compressive strength of hardened mortar, European Committee for Standardization, Brussels.

[32] NZS (1998) New Zealand Standard 4297:1998, Engineering design of earth buildings. Standards New Zealand, Wellington.

[33] Lacouture L., Bernal C., Ortiz J., Valencia D. (2007) Studies on seismic vulnerability, rehabilitation and strengthening of adobe and rammed earth houses, Apuntes, 20 (2), pp. 286-303. (in Spanish)

[34] Varum H., Silveira D., Carvalho J., Figueiredo A., Costa A. (2011) Characterization of the mechanical behaviour of adobe masonry walls. In: Proc. of Construcción com tierra. Tecnologia y Arquitectura. Congresso de tierra en Cuenca de Campos, Valladolid, pp. 225-228.

[35] Miltiadou A. (1990) Contribution to the study of hydraulic grouts for repair and strengthening of masonry structures and historical monuments. PhD Thesis, ENPC, Paris. (in French) 


\section{LIST OF TABLE CAPTIONS}

Table 1 - Consistency limits and compaction properties of the soil before and after PSD correction.

Table 2 - Composition of the unmodified mud grouts.

Table 3 - Properties of the unmodified mud grouts.

Table 4 - Results of the diagonal compression tests carried on the wallets repaired with grout B.

Table 5 - Results of the diagonal compression tests carried on the wallets repaired with grout $\mathrm{C}$. 


\section{LIST OF FIGURE CAPTIONS}

Fig. 1 - Comparison of the properties of the soils with the recommendations of Houben and Guillaud [4] for: (a) PSD; (b) consistency limits.

Fig. 2 - Compaction of the URE specimens: (a) cylinders; (b) beams; (c) wallets.

Fig. 3 - Testing setups: (a) axial compression; (b) three-point bending; (c) diagonal compression.

Fig. 4 - PSD of the mud grouts.

Fig. 5 - Repair of the URE specimens: (a) injection of the beams; (b) sealing of the cracks in a wallet;

(c) injection of the wallet.

Fig. 6 - Stress-strain curves of the URE specimens tested under axial compression.

Fig. 7 - Results of the three-point bending tests of the rammed earth specimens: (a) injection recovery ratio; (b) failure mode of a beam injected with grout A (failure occurring mostly at the interface mud grout/rammed earth); (c) failure mode of a beam injected with grout B (failure occurring partially inside the rammed earth and at the interface mud grout/rammed earth).

Fig. 8 - Shear stress-strain curves of the wallets: (a) first test of the set repaired with grout B; (b) first test of the set repaired with grout $\mathrm{C}$; (c) second test of the set repaired with grout $\mathrm{B}$; (d) second test of the set repaired with grout $\mathrm{C}$.

Fig. 9 - Failure mode: (a) WURE_2 after the first test; (b) WURE_5 after the first test; (c) WURE_2 after the second test; (d) WURE_5 after the second test.

Fig. 10 - Failure surface of the wallets after the second test: (a) presence of a gap in the grout (WURE_1); (b) injected crack with about $1 \mathrm{~mm}$ width (WURE_3). 